\title{
UJI AKTIVITAS ANTIOKSIDAN EKSTRAK METANOL DAN PROFIL KLT PARTISI CAIR-PADAT EKSTRAK DAUN JAHE BALIKPAPAN (Etlingera balikpapanensis)
}

\author{
Desy Triary Sandi*, M. Arifuddin, Laode Rijai \\ Laboratorium Penelitian dan Pengembangan FARMAKA TROPIS Fakultas Farmasi \\ Universitas Mulawarman, Samarinda, Kalimantan Timur \\ *email: Desy.triarysandi@gmail.com
}

\begin{abstract}
ABSTRAK
Tumbuhan Jahe Balikpapan (Etlingera balikpapanensis) merupakan tumbuhan asli dari Kalimantan Timur. Penelitian ini bertujuan untuk mengetahui aktivitas antioksidan dari ekstrak metanol daun Jahe Balikpapan dan juga mengetahui profil KLT partisi cair-padat dengan pelarut $n$-heksan, etil asetat dan n-butanol. Ekstraksi dilakukan dengan metode maserasi dengan menggunakan pelarut metanol kemudian dipartisi cair-padat secara berturut-turut dengan pelarut n-heksan, etil asetat dan n-butanol. Aktivitas antioksidan ekstrak metanol daun Jahe Balikpapan (Etlingera balikpapanensis) diuji dengan menggunakan metode DPPH (1,1-dyphenyl-2-picrylhidrazyl). Hasil pengujian aktivitas antioksidan ekstrak metanol daun Jahe Balikpapan (Etlingera balikpapanensis) menunjukkan nilai $\mathrm{IC}_{50} 212,71 \mathrm{ppm}$.
\end{abstract}

Kata kunci : Jahe Balikpapan (Etlingera balikpapanensis), antioksidan, DPPH, profil KLT

\begin{abstract}
Balikpapan Ginger plant (Etlingera balikpapanensis) is a native plant of East Kalimantan. This study aims to determine the antioxidant activity of metanol extract of ginger leaves Balikpapan and also determine the profile of the liquid-solid partition TLC with solvent nhexane, ethylacetate and n-butanol. Extraction was done by maceration method using metanol then the liquid-solid partition edsuccessively with solvent n-hexane, ethylacetate and n-butanol. The antioxidant activity of metanol extracts of ginger leaves Balikpapan (Etlingera balikpapanensis) tested using DPPH (1,1-dyphenyl-2-picrylhidrazyl). Results of testing the antioxidant activity of metanol extract of ginger leaves Balikpapan (Etlingera balikpapanensis) show IC50 212.71 ppm.
\end{abstract}

Keywords : Ginger Balikpapan (Etlingera balikpapanensis), antioxidant, DPPH, profile $T L C$

\section{PENDAHULUAN}

Dewasa ini penambahan antioksidan sintetik pada berbagai produk kosmetik, farmasi maupun makanan merupakan cara yang paling efektif untuk penggunaan mencegah oksidasi lemak pada produk, tetapi penggunaan antioksidan sintetik oleh masyarakat semakin berkurang, karena beberapa penelitian pada tubuh membuktikan adanya efek toksik dan 
karsiogenik pada tubuh manusia. Oleh karena itu dilakukan usaha untuk mencari antioksidan alami yang berasal dari tumbuhan yang dianggap lebih baik dari antioksidan sintetik, khususnya apabila ditinjau dari segi kesehatan (Osawa, 1992).

Tumbuhan yang berpotensi sebagai obat yang telah dibudidayakan saat ini masih sangat sedikit. Oleh karena itu, hutan indonesia masih merupakan sumber plasma nutfah tumbuhan berkhasiat obat yang potensinya perlu digali secara terus-menerus. Salah satu tumbuhan yang menarik untuk diteliti sebagai sumber antioksidan alami yaitu Jahe Balikpapan (Etlingera balikpapanensis). Daun Jahe Balikpapan (Etlingera balikpapanensis) merupakan tumbuhan asli dari Kalimantan Timur yang ditemukan di hutan dataran rendah Balikpapan Kalimantan Timur. Saat ini nama lain dan kegunaan dari Jahe Balikpapan (Etlingera balikpapanensis) masih belum diketahui atau dengan kata lain belum ada bukti empiris yang menyatakan bahwa Jahe Balikpapan memiliki aktivitas sebagai obat (Poulsen,2006).

Dari hasil penelitian sebelumnya tumbuhan yang memiliki genus yang sama yaitu etlingera menyatakan bahwa aktivitas antioksidan yang tinggi dan urutan bagian tanaman yang mengandung antioksidan dari yang paling tinggi yaitu bagian daun, kemudian bunga dan terakhir bagian rimpang (Chan dkk, 2007). Berdasarkan uraian diatas, dilakukan penelitian uji aktivitas antioksidan ekstrak metanol dengan metode DPPH (1,1-diphenyl-2picryhidrazyl) dari daun Jahe Balikpapan (Etlingera balikpapanensis).

\title{
METODE PENELITIAN
}

\begin{abstract}
Alat
Alat yang digunakan pada penelitian ini yaitu seperangkat alat maserasi, labu ukur gelap (Pyrex), tabung reaksi bertutup (Pyrex), gelas kimia (Pyrex), rotary evaporator (Büchi rotavapor $R-200$ ), spektrofotometer UV-Vis (Spectrophotometer Double Beam Halo DB209 Dynamica), waterbath, vortex (H-VM-400), timbangan analitik (Precisa XB 220A), hot plate (Stuart), dan lampu UV portable 254/366 (UVP).
\end{abstract}

\section{Bahan}

Bahan yang diteliti adalah daun Jahe Balikpapan yang diperoleh dari kawasan konservasi hutan lindung sungai wain Balikpapan. Bahan-bahan kimia yang digunakan adalah metanol, n-heksan, etil asetat, n-butanol, $\mathrm{H}_{2} \mathrm{SO}_{4}, \mathrm{DPPH}$, dan plat $\mathrm{KLT} \mathrm{GF}_{254}$.

\section{Prosedur}

\section{Penyiapan Sampel}

Sampel yang digunakan yaitu bagian daun Jahe Balikpapan yang masih utuh, hijau dan segar yang dikumpulkan dan dipisahkan dengan pengotor lainnya seperti tanah, bagian bukan daun atau bagian daun yang rusak. Setelah itu sampel ditimbang dan kemudian dicuci dengan air mengalir hingga bersih. Sampel yang telah bersih kemudian dipotong kecil-kecil dan dikeringkan terlindung dari sinar matahari, setelah itu simplisia ditimbang kembali.

\section{Ekstraksi Sampel}

Simplisia kering daun Jahe Balikpapan sebanyak 850 gram dimaserasi dengan pelarut metanol (2x24 jam). Ekstrak yang diperoleh kemudian disaring dan dipekatkan dengan rotary evaporator sehingga diperoleh ekstrak pekat metanol. 


\section{Partisi Cair-Padat}

Ekstrak pekat ( $2 \mathrm{~g}$ ) dipisahkan lebih lanjut dengan metode partisi cair-padat. Ekstrak pekat dilarutkan dengan n-heksan kemudian distirer hinnga didapatkan ekstrak larut nheksan. Perlakuan diulang dengan pelarut yang berbeda yaitu dengan etil asetat hingga didapatkan esktrak partisi etil asetat, kemudian perlakuan diulang lagi dengan menggunakan pelarut n-butanol hingga didapatkan ekstrak partisi n-butanol. Ekstrak metanol, ekstrak partisi n-heksan, etil asetat, dan n-butanol kemudian dielusi pada plat KLT dengan eluen nheksan : etil asetat (3:1) dan eluen etil asetat : metanol (1:1) setelah itu diamati pada sinar tampak (visible), sinar UV 254, sinar UV 366, dan disemprotkan $\mathrm{H}_{2} \mathrm{SO}_{4} 10 \%$.

\section{Uji Aktivitas Antioksidan}

\section{Pembuatan Larutan Uji}

Ekstrak metanol daun Jahe Balikpapan ditimbang sebanyak $10 \mathrm{mg}$ setelah itu dilarutkan dengan metanol hingga $10 \mathrm{ml}$ dan didapatkan larutan stok 1000 ppm. Kemudian dibuat larutan seri konsentrasi yaitu 50, 100, 150, 200, dan 250 ppm.

\section{Pembutan Larutan DPPH}

Ditimbang kristal DPPH untuk dilarutkan dalam metanol untuk didapatkan konsentrasi 40 ppm. Kemudian diukur panjang gelombang maksimum dari larutan DPPH dengan menggunakan spektrofotometer UV-Vis $(500-550 \mathrm{~nm})$.

\section{Pengujian Aktivitas Antioksidan}

Masing-masing larutan seri konsentrasi diambil sebanyak $2 \mathrm{ml}$ dan ditambahkan dengan larutan DPPH 40 ppm sebanyak 2 ml. Setelah itu larutan campuran divortex dan diinkubsi diruang gelap selam 30 menit. Kemudian diukur absorbansi larutan uji dengan menggunakan spektrofotometer UV-Vis dan dihitung aktivitas antioksidan dengan menggunakan persamaan:

$$
\% \text { Aktivitas Antioksidan }=\frac{\text { A.blanko }- \text { A. sampel }}{\text { A. blanko }} \times 100
$$

\section{HASIL DAN PEMBAHASAN}

\section{Profil KLT}

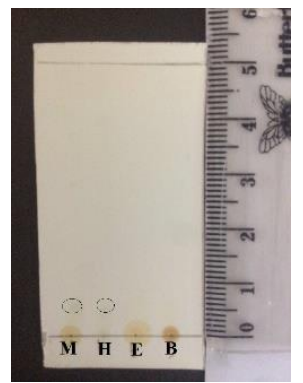

Visibel

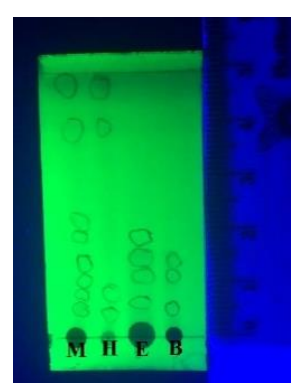

UV-254

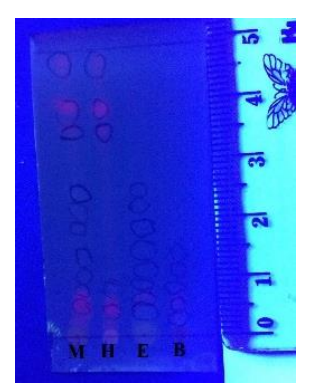

UV-366

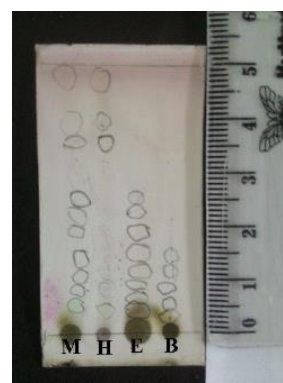

$\mathrm{H}_{2} \mathrm{SO}_{4}$

Gambar 1. Profil KLT Ekstrak Daun Jahe Balikpapan (Etlingera balikpapanensis) dengan eluen etil asetat : metanol $(1: 1)$ 


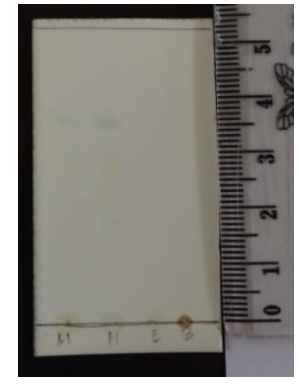

Visibel

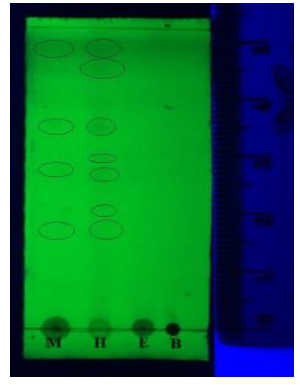

UV-254

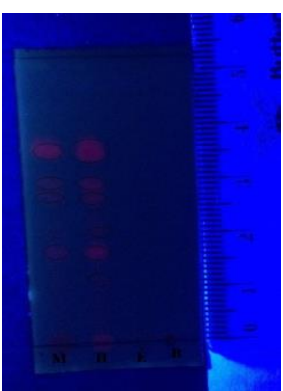

UV-366

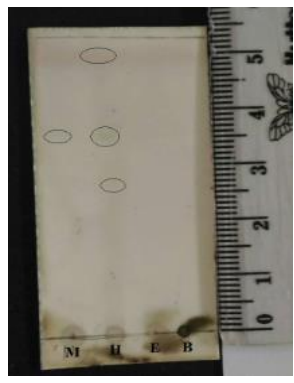

$\mathrm{H}_{2} \mathrm{SO}_{4}$

Gambar 2. Profil KLT Ekstrak Daun Jahe Balikpapan (Etlingera balikpapanensis) dengan eluen n-heksan : etil asetat $(3: 1)$

Tabel 1. Nilai Rf Ekstrak Daun Jahe Baliikpapan (Etlingera balikpapanensis)

\begin{tabular}{ccccc}
\hline \multirow{2}{*}{ Eluen } & \multicolumn{4}{c}{ Nilai Rf } \\
\cline { 2 - 4 } & Metanol & N-heksan & Etil asetat & N-butanol \\
& 0,68 & 0,94 & & \\
& 0,57 & 0,87 & & \\
n-heksan : etil asetat & 0,51 & 0,68 & & \\
$(\mathbf{3 : 1 )}$ & 0,30 & 0,57 & & \\
& 0,94 & 0,51 & & \\
& & 0,38 & & \\
& & 0,30 & & 0,31 \\
& & 0,21 & 0,22 \\
& 0,98 & 0,98 & 0,51 & 0,10 \\
& 0,79 & 0,79 & 0,45 & 0,06 \\
Etil asetat : metanol & 0,71 & 0,71 & 0,39 & \\
$(\mathbf{1 : 1 )}$ & 0,51 & 0,16 & 0,31 & \\
& 0,45 & 0,10 & 0,22 & \\
& 0,39 & 0,06 & 0,16 & \\
& 0,31 & & 0,10 & \\
& 0,22 & & 0,06 & \\
& 0,16 & & & \\
& 0,10 & & & \\
\end{tabular}

Profil KLT ekstrak daun Jahe Balikpapan (Etlingera balikpapanensis) diperoleh eluen terbaik untuk pemisahan nodanya adalah eluen n-heksan : etil asetat (3:1) dan etil asetat : metanol (1:1). Hasil elusi tersebut kemudian diamati dengan menggunakan UV-254 serta UV-366 dan menunjukkan hasil pemisahan noda yang baik. Begitu pula dengan hasil penyemprotan $\mathrm{H}_{2} \mathrm{SO}_{4} 10 \%$ tampak terjadi pemisahan noda-noda pada ekstrak metanol, ekstrak partisi n-heksan, etil asetat dan n-butanol yang dilihat dari perbedaan nilai Rf pada masing-masing noda ekstrak partisi (Tabel 1).

Uji aktivitas antioksidan dari ekstrak metanol daun Jahe Balikpapan (Etlingera balikpapanensis) dilakukan melalui reaksi peredaman radikal DPPH (1,1-diphenyl-2picrylhidrazyl). Metode DPPH dipilih karena merupakan metode yang sederhana, mudah dan cepat serta peka serta hanya memerlukan sedikit sampel. Senyawa antioksidan akan 
bereaksi dengan radikal DPPH melalui mekanisme donasi atom hidrogen sehingga menyebabkan terjadinya peluruhan warna DPPH dari ungu ke kuning. Kemampuan penangkapan radikal DPPH oleh suatu antioksidan dinyatakan dengan nilai persen penangkapan radikal (Blois, 1958). Nilai \% penghambatan radikal bebas yang tinggi menunjukkan bahwa sampel yang digunakan berpotensi sebagai antioksidan. Besarnya aktivitas antioksidan ditandai dengan nilai IC $_{50}$ yaitu besarnya konsentrasi senyawa uji yang dapat menangkap radikal sebesar $50 \%$.

Tabel 2. Aktivitas Antioksidan Ekstrak Daun Jahe Balikpapan (Etlingera balikpapanensis)

\begin{tabular}{cccc}
\hline $\begin{array}{c}\text { Konsentrasi } \\
\text { Sampel } \\
\text { (ppm) }\end{array}$ & $\begin{array}{c}\text { \% Aktivitas } \\
\text { Antioksidan }\end{array}$ & $\begin{array}{c}\text { Nilai } \\
\text { IC50 }\end{array}$ & $\begin{array}{c}\text { Keterangan* } \\
\text { (Blois) }\end{array}$ \\
\hline $\mathbf{5 0}$ & 16,575 & & \\
$\mathbf{1 0 0}$ & 27,788 & & \\
$\mathbf{1 5 0}$ & 40,585 & 212,712 & Lemah \\
$\mathbf{2 0 0}$ & 47,654 & & \\
$\mathbf{2 5 0}$ & 55,759 & & \\
\hline
\end{tabular}

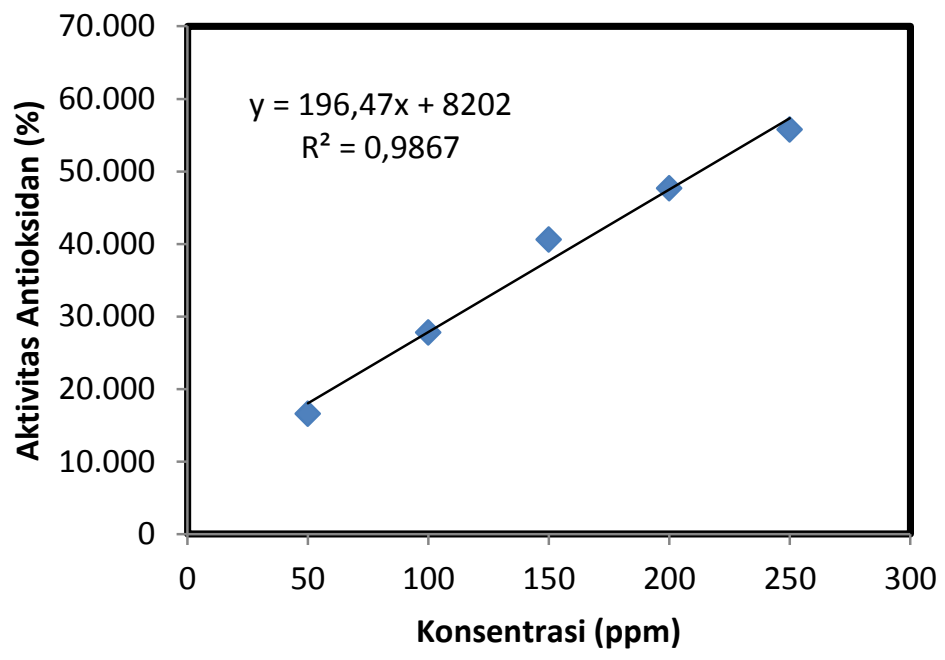

Gambar 3. Aktivitas Antioksidan Ekstrak Daun Jahe Balikpapan (Etlingera balikpapanensis)

Hasil penelitian aktivitas antioksidan ekstrak metanol daun Jahe Balikpapan (Etlingera balikpapanensis) diperoleh nilai $\mathrm{IC}_{50}$ sebesar 212,712 ppm. Menurut Blois (1958), nilai IC 50 tersebut termasuk kategori lemah. Walaupun demikian, dari hasil profil KLT ekstrak partisi n-heksan, etil asetat dan n-butanol terlihat pemisahan senyawa berdasarkan kepolarannya. Oleh karena itu, diharapkan terjadi pula pemisahan senyawa yang bersifat sinergis dan inhibitor terhadap penangkapan radikal bebas, sehingga terjadi pula peningkatan aktivitas antioksidan. 


\section{KESIMPULAN}

Profil KLT ekstrak metanol, ekstrak partisi n-heksan, etil asetat dan n-butanol daun Jahe Balikpapan (Etlingera balikpapanensis) dengan eluen n-heksan : etil asetat (3:1) dan etil asetat : metanol (1:1) memiliki pemisahan yang baik serta aktivitas antioksidan dari ekstrak metanol dengan menggunakan metode DPPH memiliki nilai IC $_{50}$ sebesar 212,712 ppm.

\section{DAFTAR PUSTAKA}

Blois, M. S. 1958. Antioxidant Determination by The Use Of Stable Free Radical. Nature, 181: 1199-1200

Chan, E. W. C., Lim, Y. Y., dan Omar Muhammad. 2007. Antioxidant and Antibacterial Activity of Leaves Of Etlingera Species (Zingiberaceae) in Peninsular Malaysia. Science Direct Food Chemistry 104. 1586-159

Osawa, T., Katsuzaki, H. Hagiwara, and T. Shibamoto. 1992. A novel antioxidant isolated from young green barley leaves. Journal of Agricultural and Food Chemistry 40: 1135 .

Poulsen, A. D. 2006. Etlingera of Borneo. Natural History publications (Borneo). 263pp 